\title{
Species of Gymnopilus P. Karst: New to India
}

\author{
Kaur $\mathbf{H}^{1^{*}}$, Kaur $\mathbf{M}^{2}$ and Rather $\mathbf{H}^{2}$ \\ ${ }^{1}$ Department of Agriculture, Baba Farid College, Muktsar road, Bathinda, India. E-mail: harwinderkaur.1@gmail.com \\ ${ }^{2}$ Department of Botany, Punjabi University, Patiala, 147002, India.
}

Kaur H, Kaur M, Rather H 2015 - Species of Gymnopilus P. Karst: New to India. Mycosphere 6(1), 165-173, Doi 10.5943/mycosphere/6/2/7

\begin{abstract}
Two species belonging to genus Gymnopilus P. Karst i.e. G. pampeanus (Speg.) Singer and G. russipes Pegler have been taxonomically described and illustrated for the first time from India and one species G. spectabilis (Weinm.) A.H. Sm. has been first time recorded from North India.
\end{abstract}

Key words - India - Gymnopilus - ornamented spores - taxonomy

\section{Introduction}

The present paper deals with species of Gymnopilus P. Karst. This genus belongs to family Strophariaceae and is characterized by bright colored (bright yellow, fulvous, red, blue etc.) carpophores, adnexed to decurrent lamellae, stipe usually with well developed annulus. Spore print very brightly and richly rusty and basidiospores are with exosporial ornamentation. Clamp connections always present. The genus is represented by 200 species the world over (Kirk et al., 2008). During the fungal forays to various localities of Punjab and Jammu \& Kashmir, collections belonging to genus Gymnopilus were collected of which 02 species viz. G. pampeanus (Speg.) Singer and G. russipes Pegler reported for the first time from India and 01 species that is $G$. spectabilis (Weinm.) A.H. Sm. is reported for the first time from North India.

\section{Materials and methods}

Standard methods for collection, preservation and description of agarics were followed, using the terminology and Field key to mushroom collector described by Atri et al. (2005). The terminology used for describing the color tone of carpophores parts and spore print is after Kornerup and Wanscher (1978). The identified specimens have been deposited in the Herbarium, Department of Botany, Punjabi University, Patiala (Punjab) India, under the Accession No. PUN. For taxonomic studies, Pegler (1977), Singer (1986) and Kirk et al. (2008) have been followed.

\section{Taxonomic observations}

Gymnopilus pampeanus (Speg.) Singer, Lilloa 22: 561, 1951.

Fig. $1(\mathrm{~A}-\mathrm{G}) ; 2(\mathrm{~A}-\mathrm{F})$.

Carpophores $6-12 \mathrm{~cm}$ in height. Pileus $2.3-8 \mathrm{~cm}$ broad, convex to applanate, broadly umbonate; golden yellow $\left(5 \mathrm{~B}_{7}\right)$ all over with orange $\left(6 \mathrm{~B}_{8}\right)$ to dark orange margin; scaly, scales appressed fibrilose, cover entire pileus, more concentrated at the umbo, rust brown to almost blackish in center; wrinkled on drying; surface dry; margin irregular, splitting at maturity, incurved when dry; cuticle fully peeling; flesh $0.3-0.5 \mathrm{~cm}$ thick, pale white, unchanging; taste and odour 


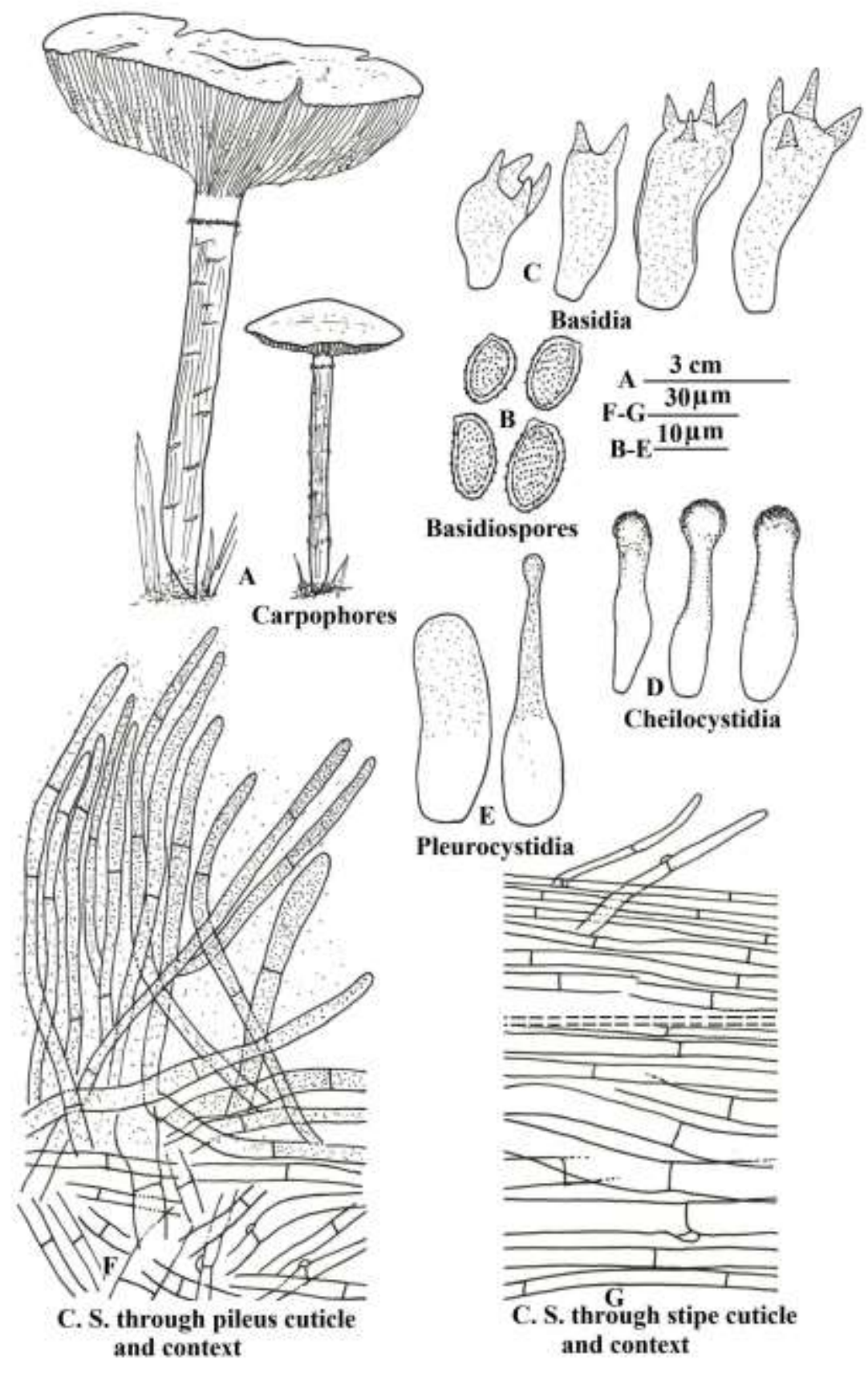

Fig. 1 A-G-Gymnopilus pampeanus (Speg.) Singer: A Carpophores. B Basidiospores. C Basidia. D Cheilocystidia. E Pleurocystidia. F C. S. through pileus cuticle \& context. G C. S. through stipe cuticle \& context.

spicy; pileal veil patchy. Lamellae broadly adanate to sinuate to slightly decurrent, unequal, lamellulae present, in 3-5 lengths, subdistant, moderately broad $(0.4-0.8 \mathrm{~cm}$ broad), light orange $\left(6 \mathrm{~A}_{5}\right)$ when young, dark orange $\left(5 \mathrm{~A}_{8}\right)$ at maturity, orange floccose deposition present deep in between the gills and at places on the gill edges; gill edges wavy, normal. Spore print greyish orange $\left(5 \mathrm{~B}_{3}\right)$. Stipe central, $5-11 \mathrm{~cm}$ long, $0.4-0.8 \mathrm{~cm}$ broad, equal in diameter throughout; pale white to light orange $\left(5 \mathrm{~A}_{4}\right)$ when young, tinged orange white $\left(6 \mathrm{~A}_{2}\right)$ at maturity; scaly, scales fibrillose, scattered all over the surface; surface not smooth rather, striate solid; annulate, annulus single, superior, membranous, dark orange $\left(5 \mathrm{~A}_{8}\right)$ upper surface with a lighter under surface, evanescent, leaving a mark on the stipe. 

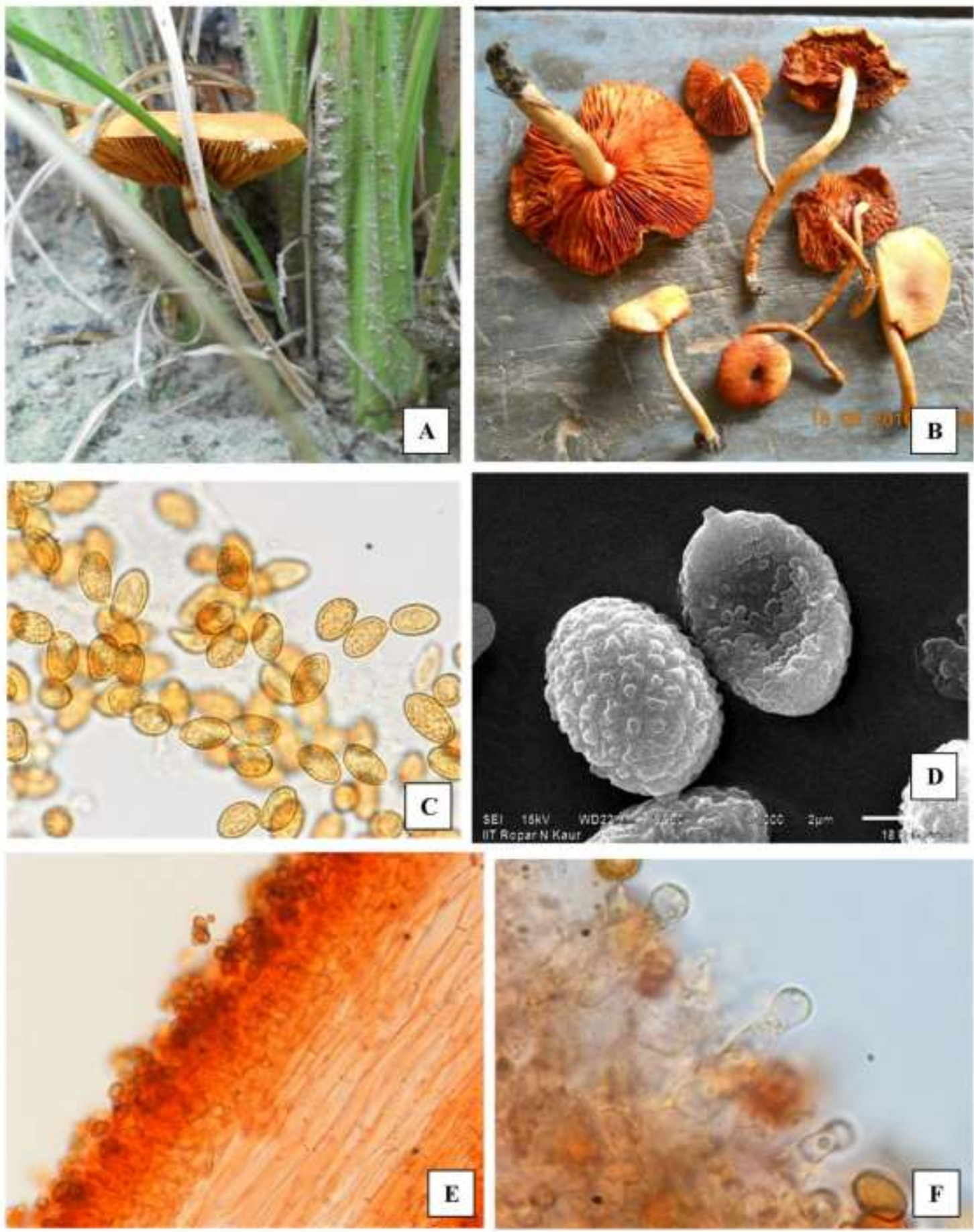

Fig. 2 A-F-Gymnopilus pampeanus (Speg.) Singer: A Carpophore growing among culms of Saccharum munja. B Carpophores with adnate gills. C Basidiospores. D SEM of Basidiospores. E Gill trama parallel. F Cheilocystidia.

Basidiospores (8.45) 9.29-10.98 (11.83) × (5.07) 5.91-6.76 $\mu \mathrm{m}$ (excluding apiculus), $(\mathrm{Q}=1.6)$ broadly ellipsoid, dextrinoid, double walled, warty, tuberculate exosporium, granular, punctuate, warty; golden in water turn golden brown in Melzer's reagent; apical pore absent; apiculate, apiculus $0.84-1.69 \mu \mathrm{m}$ long. Basidia 15.21-28.73 $\times 7.6-10.14 \mu \mathrm{m}$, clavate, granular, $-2,-$ 4 spored, mostly -4 spored; sterigmata 4.22-7.6 (8.45) $\mu \mathrm{m}$ long, swollen, granular. Pleurocystidia lacking in PUN 5952 rarely present in PUN 5953 which are 27.88-35.49 $\times 7.6-10.14 \mu \mathrm{m}$, very rare, cylindrical to obclavate with long neck having capitate tips, thickly granular in neck. Cheilocystidia (11.83) $16.9-25.35 \times 4.22-6.76(8.45) \mu \mathrm{m}$, versiform, ventricose, obclavate, lageniform to lecythiform, with encrustrated capitate apices, abundant; gill edges sterile. 
Carpophore context homoiomerous. Pileus cuticle hyphal, made up of horizontally tangled gelatinized, septate hyphae giving rise to a regular turf of projecting repent, granular, 3.94-9.85 (15.76) $\mu \mathrm{m}$ broad hyphae; context made up of 3.94-17.73 (27.58) $\mu \mathrm{m}$ broad, loosely tangled septate hyphae. Hymenophoral trama hyphal, regular, made up of 5.07-23.66 $\mu \mathrm{m}$ broad, hyaline hyphae with some deposition at septa everywhere in gill trama hyphal. Stipe cuticle hyphal, made up of 3.94-9.85 (13.79) $\mu \mathrm{m}$ broad hyphae, longitudinally arranged with few projecting hyphae; context made up of 7.88-15.76 $\mu \mathrm{m}$ broad, septate hyphae. Clamp connection present in the pileus and stipe cuticle, lacking at the base of basidia.

Collection examined- India, Punjab, Faridkot (196 m), village Bargari, growing scattered among the culms of Saccharum munja, along river roadside, Harwinder Kaur, PUN 5952, August 18, 2010; village Bajakhana, graminicolous, growing scattered among the culms of Saccharum munja, along river roadside, Harwinder Kaur, PUN 5953, August 15, 2011.

Distribution and ecology - Pegler (1977) recorded G. pampeanus from Kenya on the Eucalyptus stump in mid August, 1953 Rayner; later Pegler (1977) collected it from Tanzania growing on dead Eucalyptus stump in late April, 1968; whereas the collections of Gill in Pegler (1977) were collected this species in late September, 1962, growing on living Eucalyptus tree, from Tanzania, while from Uganda, French collected this species in caespitose habit on tree stump in early April, 1957 given by Pegler (1977); later Cock in 2000 recorded it on living tree of Eucalyptus in Argentina. Presently this species has been recorded scattered among culms of Saccharum munja in mid August from the sub-arid zone of Punjab.

Remarks - The presently worked out collections PUN 5952, 5953 are quite confusing between Gymnopilus spectabilis and Gymnopilus pampeanus. Even Pegler (1977) has regarded G. pampeanus as a tropical form of the well known north temperate species G. spectabilis. Our collections fall more close to G. pampeanus as described by Pegler $(1977,1983)$ and Pegler and Rayner (1969). G. pampeanus is characterized by its large bright yellow orange coloured carpophores, stipe exannulate or annulus soon evanescent, absence of pleurocystidia or of very rare occurrence, cheilocystidia with encrustrated capitate apices. This constitutes a new fungus record for India.

Edibility - Unknown.

Gymnopilus russipes Pegler, Kew Bull. Addl. Sr, 9: 547, 1983.

Fig. 3 (A-F); 4 (A-D).

Carpophores 7.6-8.3 cm in height. Pileus $5.7-5.9 \mathrm{~cm}$ broad, convex; surface white with yellowish gray $\left(2 \mathrm{~B}_{2}\right)$ tinge; umbo absent; margin irregular, black deliquescent, surface moist; scaly, scales squarrose type aggregated at the center; cuticle half peeling; flesh offwhite, unchanging, upto $0.3 \mathrm{~cm}$ thick; pileal veil absent; light brown $\left(6 \mathrm{D}_{4}\right)$ scales in patches over umbo. Taste unknown, odour mild. Lamellae adnexed, distant, unchanging; dark blond $\left(5 \mathrm{D}_{4}\right)$ when young, grayish brown $\left(7 \mathrm{E}_{3}\right)$ at maturity, broad (upto $0.5 \mathrm{~cm}$ broad); lamellulae present; gill edges wavy, whitish. Spore print deposit orange white $\left(5 \mathrm{~A}_{2}\right)$. Stipe central, upto $4.9 \mathrm{~cm}$ long, $1.2 \mathrm{~cm}$ broad near the apex, 1.4 $\mathrm{cm}$ at middle and upto $1.6 \mathrm{~cm}$ broad at base, offwhite; veined; watery to brown with bruising base; base turnip like with a number of rhizomorphs; colour of base, brownish orange $\left(7 \mathrm{C}_{6}\right)$ to moderate orange.

Basidiospores 7.15-10.74 $\times 5.37-8.05 \mu \mathrm{m}$ (excluding apiculus), $(\mathrm{Q}=1.0)$, subglobose to ovoid; punctate; verrucose to tuberculate; double walled, rough walled; apiculate, apiculus 0.9-1.8 $\mu \mathrm{m}$ long; apiculus excentric; short spines, warts present in pairs as well as isolated; germpore absent. Basidia 25-35 $\times 7-12 \mu \mathrm{m}$, claviform to utriform, 2-4 spored, granular; sterigmata 3.58-5.37 $\mu \mathrm{m}$ long. Cheilocystidia $21.48-39.38 \times 7-12 \mu \mathrm{m}$, claviform to ventricose, double walled, granular. Pleurocystidia absent; gill edges heteromorphous.

Carpophore context homoiomerous. Pileus cuticle hyphal, made up of $4.5-6 \mu \mathrm{m}$ broad radially tangled septate hyphae with upper apices granular; pileus context cellular. Hymenophoral trama regular. Stipe cuticle hyphal, made up of longitudinally tangled close $6.7-16 \mu \mathrm{m}$ broad septate hyphae. Clamp connections present throughout. 

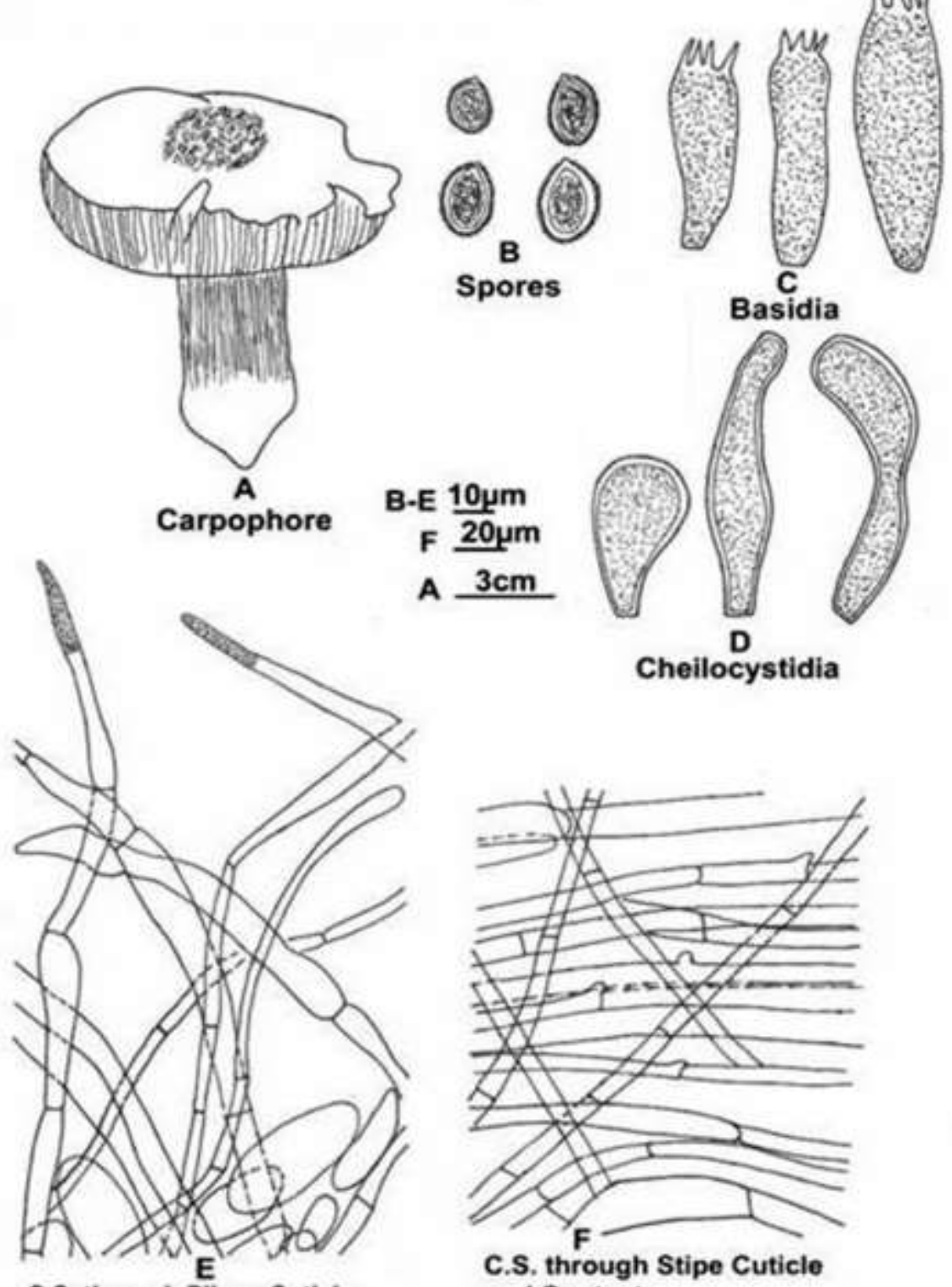

C.S. through Pileus Cuticle and Context

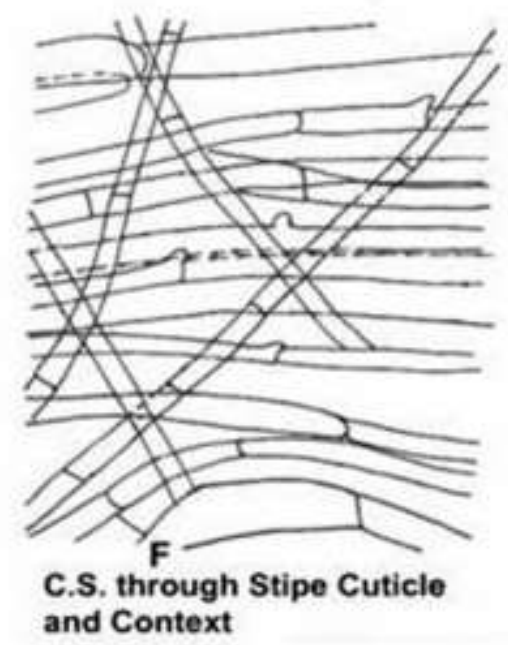

Fig. 3 A-F-Gymnopilus russipes Pegler: A Carpophore. B Spores. C Basidia. D Cheilocystidia. E C. S. through pileus cuticle \& context. F C. S. through stipe cuticle \& context.

Collection examined - India, Jammu and Kashmir, Baramulla, village Soyan Saidnar (1315 m) growing in groups in the mixed forest. Hilal Ahmad Rather, PUN 5197, PUN 5185, May 15, 2012.

Distribution and ecology - Pegler (1983) collected G. russipes growing on rotten wood described in Agaric flora of the Lesser Antilles. Presently, found growing in groups in the mixed forest of Jammu and Kashmir during mid of May.

Remarks - The morphology and internal anatomy of the presently examined specimen are in agreement with Gymnopilus russipes Pegler, as given by Pegler (1983). The significant features of G. russipes are a constantly reddish brown stipe with an expanding turnip like base with numerous rhizomorphs, base brownish orange and in this species the velar structures are lacking even in the young stages further, the spores are verrucose. Presently, this species has been reported for the first time from India. 

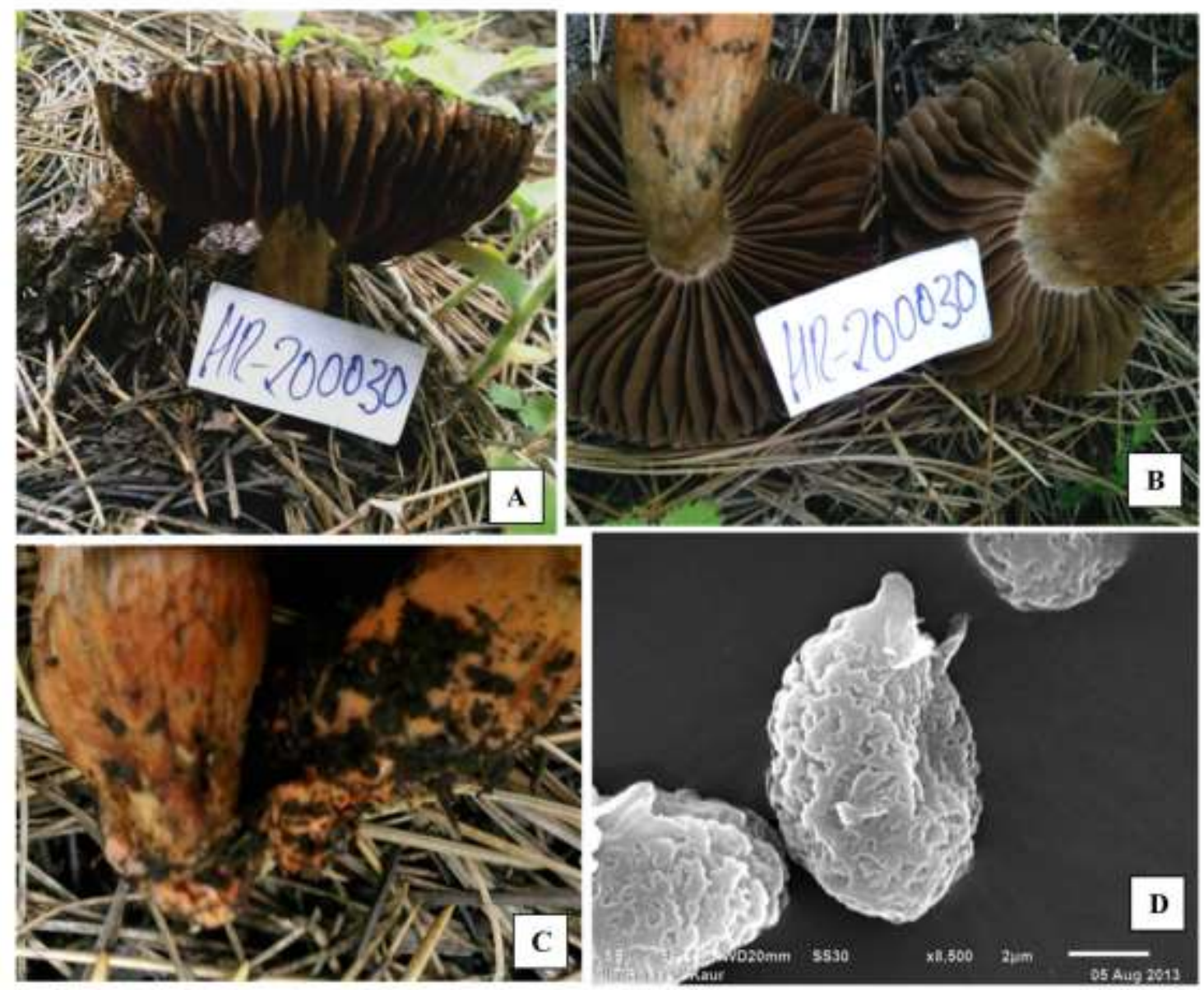

Fig. 4 A-D-Gymnopilus russipes Pegler: A Carpophore growing in its natural habitat. B Underview of carpophores showing adnexed dark blond lamellae. C Stipe showing turnip base with rhizomorphs. D SEM of Basidiospores.

Gymnopilus spectabilis (Weinm.) A.H. Sm., Mushrooms in their natural habitats: 471, 1949.

Fig. 5 (A-G); 6 (A-F).

Carpophore $7.5 \mathrm{~cm}$ in height. Pileus $5.6 \mathrm{~cm}$ broad, convex; broadly umbonate, surface moist, greyish yellow $\left(4 \mathrm{~B}_{5}\right)$ in center, pastel yellow $\left(3 \mathrm{~A}_{4}\right)$ towards periphery; scaly, scales appressed fibrillose, cover the entire pileus surface, maximum in center; margin regular, splitting at maturity; cuticle fully peeling; flesh $0.6 \mathrm{~cm}$ thick, light yellow, unchanging; taste sour; odour mild. Pileal veil patchy, orange yellow $\left(4 \mathrm{~B}_{8}\right)$. Lamellae adnexed to broadly adanate; unequal, in 3 lengths, lamellulae present; subdistant; broad (upto $0.8 \mathrm{~cm}$ broad); light yellow $\left(4 \mathrm{~A}_{4}\right)$ in young, unchanging on bruising, become brown $\left(6 \mathrm{E}_{3}\right)$ on drying; gill edges lacerate; fragile. Spore print orange yellow $\left(4 \mathrm{~B}_{8}\right)$. Stipe central, $6 \mathrm{~cm}$ long, $0.7 \mathrm{~cm}$ broad near attachment to the pileus, $0.4 \mathrm{~cm}$ broad near the base, slightly tapering downward, pale yellow $\left(3 \mathrm{~A}_{3}\right)$, solid, scaly, scales fibrillose, all over the stipe; annulate, annulus short skirt like pendulous, membranous with rough upper surface due to spore deposition, superior, orange yellow $\left(4 \mathrm{~B}_{8}\right)$.

Basidiospores (7.6) 8.45-10.14 × 5.91-6.76 $\mu \mathrm{m}$ (excluding apiculus), $(\mathrm{Q}=1.4)$ ellipsoid, golden brown, double walled, walls dark brown, inner spore wall seems to be spiny, outer wall rough, densely verrucose ornamented, appear as beaded, catenulate chains on the surface; apical pore absent; apiculate, apiculus 0.84-1.69 $\mu \mathrm{m}$ long. Basidia 15.21-23.66 × 5.9-9.29 $\mu \mathrm{m}$, clavate, granular upper part, $-2,-4$ spored, mostly -4 spored; sterigmata very long, 3.38-6.76 $\mu \mathrm{m}$ long. Pleurocystidia 16.9-22.81 $\times 5.07-9.29 \mu \mathrm{m}$, claviform with granular tips, very rare; Cheilocystidia $15.21-25.35 \times 5.07-6.76 \mu \mathrm{m}$, lecythiform with short constricted neck and rounded apices, granular throughout with thickly granular apices; abundant; gill edges sterile. 


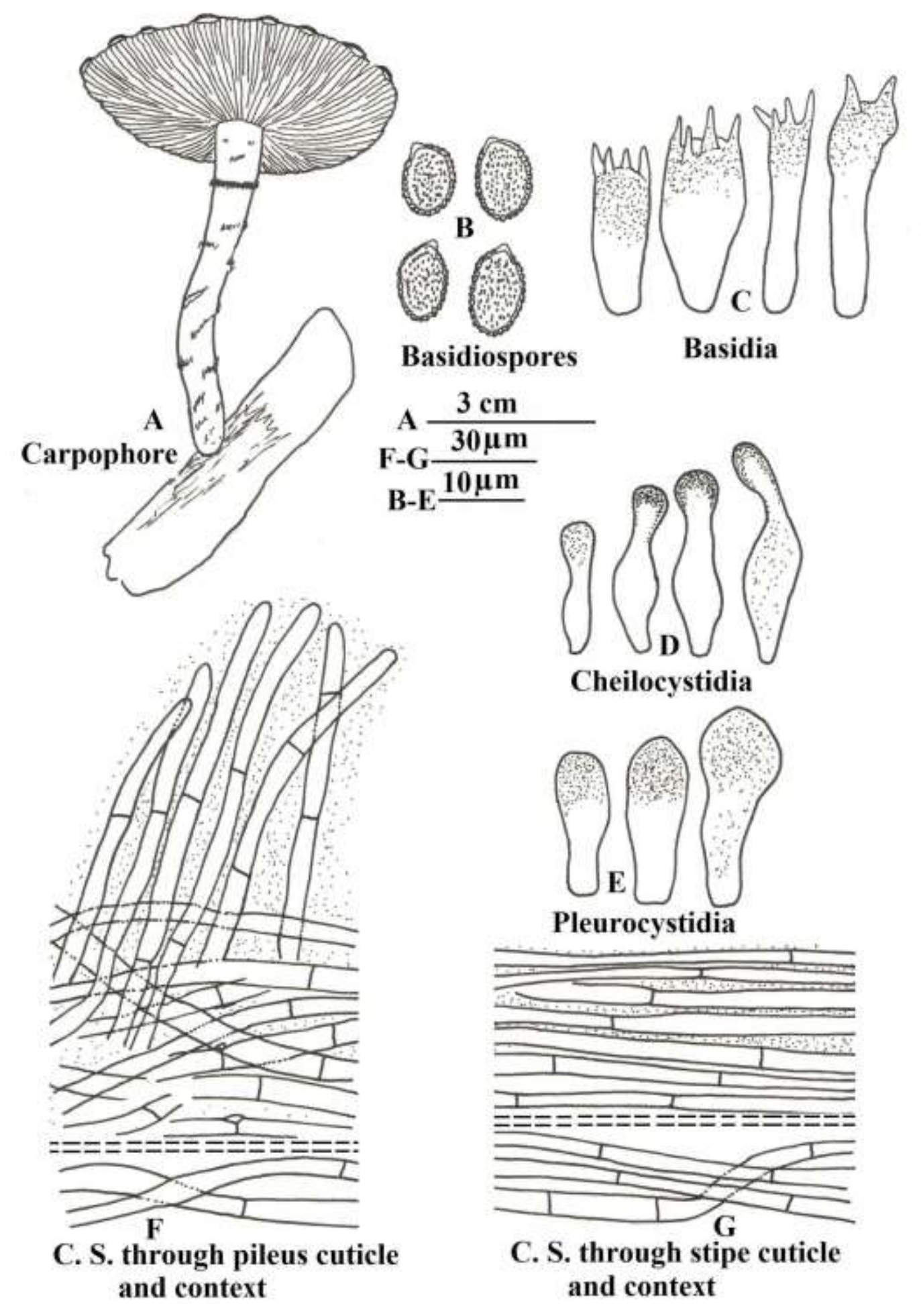

Fig. 5 A-G-Gymnopilus spectabilis (Weinm.) A.H. Sm.: A Carpophore. B Basidiospores. C Basidia. D Cheilocystidia. E Pleurocystidia. F C. S. through pileus cuticle \& context. G C. S. through stipe cuticle \& context.

Carpophore context homoiomerous. Pileus cuticle hyphal, made up of horizontally tangled, septate hyphae giving rise to a regular turf of projecting 5.91-9.85 (11.82) $\mu \mathrm{m}$ broad, septate hyphae forming a sparsely populated turf; pileus context hyphal; Hymenophoral trama hyphal, regular, parallel. Stipe cuticle hyphal, gelatinized, made up of longitudinally tangled 3.94-7.88 $\mu \mathrm{m}$ broad, septate, hyphae, arranged parallel. Clamp connections present. 

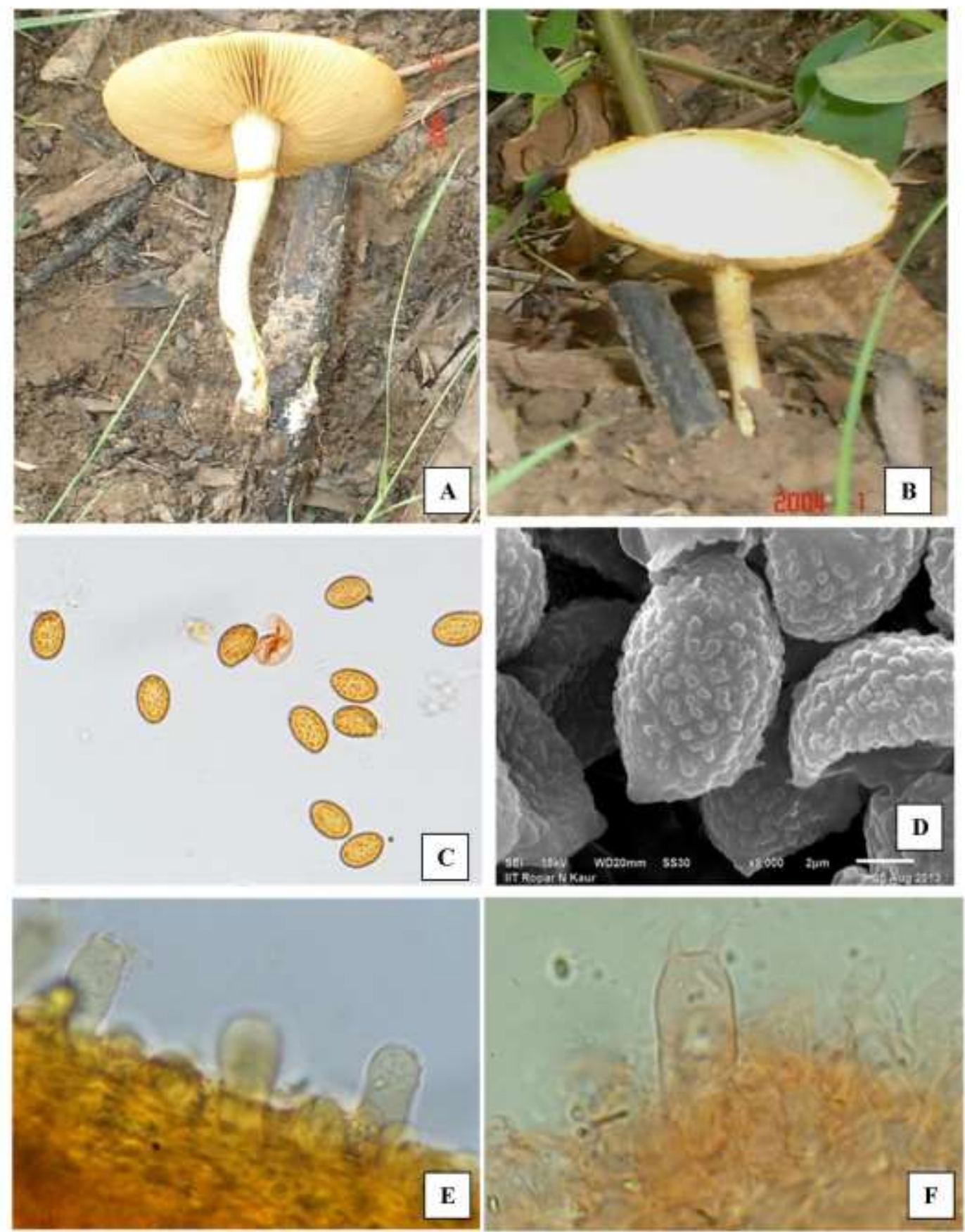

Fig. 6 A-F-Gymnopilus spectabilis (Weinm.) A.H. Sm.: A Carpophore growing on wooden log of Eucalyptus. B Carpophore with appendiculate pileal veil. C Basidiospores. D SEM of Basidiospores. E Pleurocystidia. F Basidia.

Chemical colour reaction - Basidia and gill trama becomes pale yellow in $\mathrm{KOH}$.

Collection examined - India, Punjab, Patiala (251 m), village Khedi Gandian, lignicolous, growing solitary on wood log of Eucalyptus, Munruchi Kaur, Harwinder Kaur, Yadwinder Singh, PUN 5951, July 22, 2009.

Distribution and ecology - Smith (1949) reported G. spectabilis from central and Eastern States and Southern States of Canada, growing in caespitose clusters on dead wood of Conifers during the late summer and fall; Natarajan and Raman (1984) observed that G. spectabilis is almost confined to living or dead Eucalyptus tree. Presently, also found on wood logs of Eucalyptus. 
Remarks - The external morphology and microscopic details of the presently worked out collection closely resembles the details given for Gymnopilus spectabilis (Weinm.) A.H. Sm. by Smith (1949), Pegler (1983), Natarajan and Raman (1984) and Singer (1986). G. spectabilis is characterized in possessing cheilocystidia with a slender neck with small capitate apices lacking any terminal thickening. PUN 5951 has also been collected from dead wood of Eucalyptus thus confirming the observation of Natarajan and Raman (1984). This species has been reported from Tamil Nadu by Natarajan and Raman (1984) from South India, it is not reported from North India.

Edibility - According to Walters (1965), this species is hallucinogenic.

\section{Acknowledgements}

Thanks are due to the Head, Department of Botany, Punjabi University, Patiala for providing laboratory facilities. We are indebted to UGC and DST for financial assistance.

\section{References}

Atri NS, Kaur A, Kour H. 2005 - Wild Mushrooms- Collection and Identification. In: Frontiers Mushroom Biotechnology. (Rai RD, Upadhyay RC, Sharma SR eds). NRCM Chambaghat, Solan, pp. 9-26.

Kirk PM, Cannon PF, Minter DW, Stalpers JA (eds). 2008 - Dictionary of Fungi, $10^{\text {th }}$ edn. CABI Publishing, UK.

Kornerup A, Wanscher JH. 1978 - Methuen Handbook of Colours, $3^{\text {rd }}$ edn. Eyre Methuen. London, 252.

Natarajan K, Kumaresan V, Narayanan K. 2005 - A checklist of Indian Agarics and Boletes (19842002). Kavaka 33: 61-128.

Natarajan K, Raman N. 1984 - South Indian Agaricales. A preliminary study on some dark spored species. International Books and Periodicals Supply Services, New Delhi. pp. 1-204.

Pegler DN, Rayner RW. 1969 - A contribution to the Agaric Flora of Kenya. Kew Bull. 23: $347-$ 412.

Pegler DN. 1977 - A preliminary agaric flora of East Africa. Kew Bull. Addi., Ser.6. Her Majesty Stationary Office Pp. 615.

Pegler DN. 1983 - Agaric flora of the lesser Antitles. Kew Bull. Addi. Ser. 9: 1-668.

Singer R. 1986 - The Agaricales in Modern Taxonomy. 4th Ed. Sven Koeiltz Scientific Books, Germany. pp. 981.

Smith AH. 1949 - Mushrooms in their Natural Habitats. Hafner Press, New York, pp. 626.

Walters MB. 1965 - Pholiota spectabilis, a hallucinogenic fungus. Mycologia, 57: 837-38. 